\title{
Measuring socio-emotional skills in schools: simple questionnaires outperform behavioral tasks
}

\author{
Mélusine Boon-Falleur $^{\mathrm{a}, 1}$, Adrien Bouguen ${ }^{\mathrm{b}}$, Axelle Charpentier ${ }^{\mathrm{c}}$, Yann Algan ${ }^{\mathrm{d}}$, Élise Huillery ${ }^{\mathrm{e}, 2}$, and Coralie Chevallier ${ }^{\mathrm{f}, 2}$ \\ a Institut Jean Nicod, Département d'études cognitives, ENS, EHESS, PSL University, 29 rue d'Ulm, 75005 Paris, France \\ banta Clara University, 500 El Camino Real, Santa Clara, CA 95053, USA \\ ${ }^{c}$ DEPP, Ministry of Education, 65 rue Dutot, 75015 Paris, France \\ ${ }^{\mathrm{d}}$ Sciences Po, Observatoire Français des Conjonctures Economiques, Paris, France, 28, rue des Saints-Pères, 75006 Paris, France \\ 'Université Paris Dauphine, PSL, Place du Maréchal de Lattre de Tassigny, 75016 Paris, France \\ ${ }^{\mathrm{f}}$ Laboratoire de Neurosciences Cognitives et Computationnelles, INSERM, ENS, PSL University, 29 rue d'Ulm, 75005 Paris, France \\ ${ }^{1}$ Corresponding authors: mboonfalleur@clipper.ens.fr; coralie.chevallier@ens.fr \\ ${ }^{2}$ contributed equally
}

\begin{abstract}
Recent empirical research has shown that improving socioemotional skills such as grit, conscientiousness and self-control leads to higher academic achievement and better life outcomes. However, both theoretical and empirical works have raised concerns about the reliability of the different methods used to measure socio-emotional skills. We compared the reliability and validity of the three leading measurements methods - a studentreported questionnaire, a teacher-reported questionnaire, and a behavioral task - in a sample of 3,997 French students. Before analyzing the data, we polled 114 experts in cognitive development and education economics; most experts in both fields predicted that the behavioral task would be the best method. We found instead that the teacher questionnaire was more predictive of students' behavioral outcomes and of their grade progression, while the behavioral task was the least predictive. This work suggests that researchers may not be using optimal tools to measure socio-emotional skills in children.
\end{abstract}

Self-control | Grit | Conscientiousness | Academic performance | Validation Correspondence: mboonfalleur @clipper.ens.fr

The Importance of Socio-Emotional Skills. What makes a student successful in school? Studies have shown that socio-emotional skills such as self-control or self-esteem rival cognitive skills in predicting academic achievement (110) and other life outcomes such as employment, earnings, health, and criminality (11-14). Among these socioemotional skills, conscientiousness, self-control, and grit have been identified as playing an important role for academic achievement and future life outcomes (15-20). Recent empirical works have recently demonstrated that interventions to increase these skills in children led to an increase in academic performance, suggesting a causal link between these variables (21-25). In light of these findings, policy makers and practitioners around the world have implemented programs aimed at developing socio-emotional skills in students (e.g., KIPP charter schools in the United States, the Singapour Positive Education Network, the Contruye-T program in Mexico, and Energie Jeunes in France).

The domain of socio-emotional skills is the subject of interdisciplinary research, spanning fields from economics to development psychology and professionals from academics to educators. As a result, many different terms and theoretical frameworks are used to describe and understand these skills (26). For example, in the economics literature, scholars often use the phrase "non-cognitive skills", while some education experts prefer to talk about "character skills". In this article, we use the term socio-emotional skills as it is widely used in the psychological literature.

Measurement Issues with Socio-Emotional Skills. Imprecise measures of socio-emotional skills will lead to imprecise conclusions and possibly misleading policy recommendations, especially in small sample studies (27). Therefore, researchers and policy makers should be cautious when selecting tools to measure socio-emotional skills. Three main methods are currently used in the literature -self-reported questionnaires, third-party questionnaires (e.g., parents or teachers), and behavioral tasks- each of which is exposed to potential biases (28). Self-reported questionnaires are affected by the "social desirability bias", which arises when respondents consciously or unconsciously provide answers that might be viewed favorably by others. They can also be affected by the fact that different people can have different standards or reference points, which may lead two people that are objectively identical on a given trait (say self-control or grit) to report different scores on that trait because the reference point of their group is different. In addition, responses may be affected by the cognitive skills of the respondent and her ability to understand the questions asked $(29,30)$. Thirdparty questionnaires are also exposed to the "reference bias" and may be further flawed by subjective impressions or by misinterpretations of behavior, as well as poor observation and thus information on that behavior. By contrast, behavioral tasks provide objective measures and are less affected by these biases. However, they are influenced by cognitive factors such as response time, accuracy or IQ which can be unrelated to the construct at hand (31). In addition, behavioral tasks measure performance at the time of the experiment, and not the average level of performance over a longer period of time (32). For a detailed account of potential limitation with each method of measure, see (33) and (34). 
The Present Research. Despite these validity concerns, no study has directly compared different methods to measure socio-emotional skills. The overall purpose of this paper is to compare the reliability of student-reported questionnaires, teacher-reported questionnaires, and a behavioral task to measure socio-emotional skills and to identify which is the most valid tool. To shed light on this issue, we measured conscientiousness (the desire to do a task well), self-control (the ability to regulate behavior, attention and emotions in the service of valued goals), and grit (the ability to persevere towards long-term goals) using three standardized methods of measurement. We selected methods that have been validated for their reliability and consistency and are widely used in experimental works. The student-reported questionnaire includes items related to conscientiousness from the Big Five Inventory (35), the Short Grit Scale (36), and the Domain-Specific Impulsivity Scale for children (37) which measures self-control. The teacher-reported questionnaire was composed of the Character Growth Card (38), a validated tool used in many educational programs to measure students' socio-emotional skills, including self-control and grit. For the behavioral task, we used the Academic Diligence Task, an experimentally validated tool to measure self-control and grit in students (39). During this task, students had to chose between solving simple math problems or watching entertaining videos. Before the beginning of the task, the experimenter explained that solving math problems is important to develop the brain and students were encouraged to solve as many math problems as possible. Students were also told that their answers would be anonymous and confidential, and that they were completely free to pick either math exercises or videos. The task consisted of three block of three minutes. These methods are used interchangeably in the literature to measure grit, self-control and conscientiousness in students. To compare these measures, we first assessed their reliability, i.e. whether each measure is consistent across time, raters, and items, using long-term stability and Cronbach's Alpha. Second, we assessed the validity of each method by testing whether the measures of socio-emotional skills correlate with behaviors related to the same psychological constructs. Time spent doing homework and discipline at school are both behavioral measures that we expect to correlate highly with conscientiousness, self-control, and grit. In addition, the literature has shown that these socio-emotional skills have an impact on the development of linguistic, cognitive and academic aptitudes (21). We therefore expect that students who rate higher on conscientiousness, self-control, and grit scales will be more likely to have higher grades or to see their grades improve over time. Valid measures should thus predict school behavior and academic performance.

Finally, we polled a sample of 114 experts in both the economics and cognitive sciences before completing the data analysis to prevent hindsight bias, that is, the tendency for researchers to think "I knew that already" (40). A link was sent out to researchers via the network of the Paris School of Economics, the École Normale Supérieure, and Université Paris

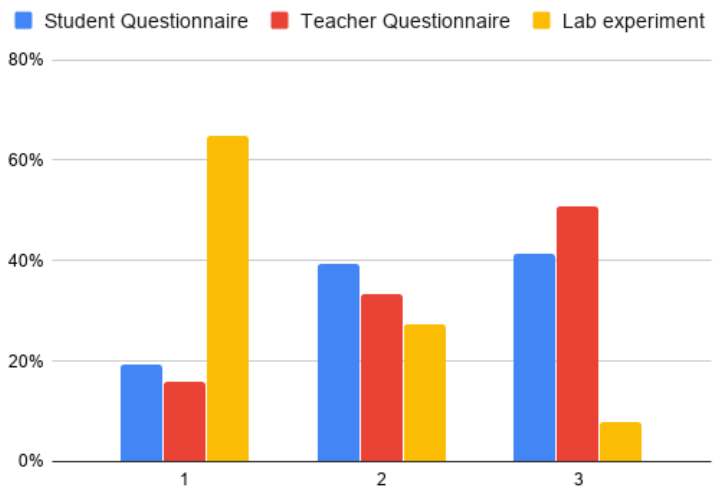

Fig. 1. Results from expert survey. A total of 114 experts were surveyed online and ranked the three measures of socio-emotional skills from (1) best method to (3) worst method. Amongst these experts, 45 came from the field of economics, 36 from the cognitive and psychology sciences, and 33 from other fields such as biology or anthropology. The table shows the percentage of experts that selected a specific method for each rank. The majority of experts (65\%) ranked the behavioral task as the best method.

Dauphine. The survey asked respondents to rank the three measures of socio-emotional skills in middle-schoolers: 1standardized child self-reported questionnaire, 2- standardized teacher-reported questionnaire, and 3- standardized lab experiment. We found that a vast majority of experts believe that behavioral tasks are better than teacher-reported questionnaires $(81 \%)$ or believe that behavioral tasks are better than self-reported questionnaires (76\%). Detailed results can be seen in Figure 1. The respondent's research speciality economics or cognitive science - did not affect responses.

\section{Method}

Participants. We collected data in a sample of 97 French REP $^{1}$ middle schools located across the country. Seven students per class were randomly selected among all sixth and seventh grade's students to participate in our study. Students were 13 years old on average $(\mathrm{SD}=0.78), 88 \%$ were of French nationality, and 52\% benefited from financial aid, which is about 14 points above the national rate. Data collection was embedded in a larger study aimed at measuring the impact of a low intensity intervention in middle school students to improve academic achievement (25). To ensure no confounding with the larger study intervention, we sampled students only from the control group.

All students in the experiment completed the questionnaire and the behavioral task, therefore missing values came from random issues with extractions from school records. We excluded a total of 2,006 students from our sample for whom data was missing. However, to ensure that our results were not affected by attrition, we conducted the same analysis on the total sample using imputations and found no difference (see Appendix Figures C8 to C11). The data collection took place over three years. The first cohort consisted of 784 students in the sixth grade during the spring of 2015. The second cohort consisted of 1,166 students in sixth grade and 1,117

${ }^{1}$ REP (Réseau d'Éducation Prioritaire) are schools receiving aid from the government to address the academic and socioeconomic needs of students. 
students in seventh grade in the spring of 2016. The third cohort consisted of 930 students in seventh grade in the spring of 2017. A total of 3,997 separate measures were included in our study. Among those, a subset of these measures come from the same students who were randomly selected in both the first and second cohort, or in both the second and the third cohort.

Experimental design. Research assistants were dispatched across the French territory to collect data in each middle school. After training, research assistants collected administrative data from the school and administered both the behavioral task and the student questionnaire during normal school hours. Students each received earbuds and a digital tablet to complete both the questionnaire and the behavioral task. Research assistants also distributed the teacher questionnaire in paper format to one teacher per class and collected the answers a few days later. Research assistants and the teachers involved in the study were blind to the purpose of the experiment and the hypothesis being tested.

Measures of socio-emotional skills. To measure socioemotional skills, we used three separate instruments: a student-reported questionnaire, a teacher-reported questionnaire and a behavioral task. When the instruments were only available in English, the material was translated from English to French using the Back Translation method to ensure a high degree of reliability. The French version of the questionnaires can be found in the Appendix (see Materials Section in Appendix).

Student-reported questionnaire. Students completed a battery of self-reported questionnaires on digital tablets. They were told that their answers would remain anonymous and confidential. All responses were encoded on a scale from 1: not at all like me to 5: very much like me. Some items in each scale were inverted on the questionnaire to make sure that students were not systematically choosing the same answer. Answers were re-coded and averaged such that a higher score always indicates more agreement with the construct. Students answered four questions from the Big Five Inventory to assess conscientiousness (35). Students answered eight questions related to grit adapted from the Short Grit Scale, four questions related to consistency of interest and four questions related to perseverance of effort (36). A grit composite index was calculated as the mean of the answer to all eight questions, with higher scores indicating more grit. Students answered eight questions related to self-control from the Domain-Specific Impulsivity Scale for children (37). Four questions were related to self-control in the domain of school work and interpersonal relationships. A self-control composite index was calculated as the mean of the answer to all eight questions, with higher scores indicating more self-control.

Teacher-reported questionnaire. One teacher per class completed a questionnaire during normal school hours. Questionnaires were translated from the Character Growth Card (38) and the answers ranged from 1: this doesn't resemble the student at all to 5: this completely resembles the student. Within the Character Growth Card, teachers had to answer three questions related to grit and eight questions related to self-control for each student. A grit composite index was calculated as the mean of the answer to all three questions, with higher scores indicating more grit. A self-control composite index was calculated as the mean of the answer to all eight questions, with higher scores indicating more self-control.

Behavioral task. For the behavioral task, we replicated the Academic Diligence Task developed in Galla et al., 2014; the pre-registration for the replication is available on the project's OSF page https://osf.io/afzgx (39). This task was designed to measure self-control and grit in students. Students had to choose between solving simple math questions and watching entertaining videos (e.g., a movie trailer or music videos). Before the beginning of the task, the experimenter explained that solving math problems is important to develop the brain and students were encouraged to solve as many math problems as possible. Students were also told that their answers would be anonymous and confidential, and that they could do whatever they wanted. The task consisted of three blocks of three minutes during which the students could choose between solving one digit subtractions or watching entertaining videos. Our outcome variables were the total number of attempted subtractions, the total number of subtractions correctly solved, and the percentage of time they spent solving math problems. For a complete description of the task and replication, please see the Appendix.

\section{Measures of behavioral outcomes and academic} achievement. For each student, we extracted data on disciplinary outcomes from school records: number of late arrivals, number of absences, number of sanctions, and number of disciplinary actions ${ }^{2}$. On average, students arrived 4.8 times late at school during the year $(\mathrm{SD}=8.3)$, has a total of 3.0 days of unjustified absences $(\mathrm{SD}=6.8)$, received 3.5 sanctions $(\mathrm{SD}=7.5)$ and 0.3 disciplinary actions $(\mathrm{SD}=$ 1.2). We standardized, inverted and summed these four measures to create a disciplinary index, higher values indicating more disciplined behavior. Each student was also asked to report the time she spent on homework in the last two days in the student-reported questionnaire. Given that time spent doing homework may be sensitive to the day of the week, we recorded the day of the week when the student completed the survey and added it as a control. In addition, we also collected students' math and French GPA. French and math average GPA were respectively 12.1 and 11.9 out of $20(\mathrm{SD}=$ 3.4 and 3.9). For a subset of students, we had access to their school records in the years following our study. This allowed us to measure the change in the disciplinary index and the change in French and math GPA from one year to the next for these students.

\footnotetext{
${ }^{2}$ Sanctions are often hours of detention, while disciplinary actions are more severe than sanctions and are decided collectively by the school administration
} 
Statistical analysis. To estimate the validity of each method of measure, we used ordinary least square to estimate the following equation:

$$
Y_{i s}=\alpha+\beta N C_{i s}+\gamma X_{i s}+\theta_{s}+\epsilon_{i s}
$$

where $Y_{i s}$ is the standardized behavioral or school outcomes (e.g., time spent doing homework, disciplinary index, French or math GPA) for individual $i$ in school $s, N C_{i s}$ is the standardized measure of a socio-emotional skill (e.g., BIG5 conscientiousness score, number of subtractions correctly solved, etc.), $X_{i s}$ is a vector of baseline covariates (including the school year of the student), $\theta_{s}$ are school fixed effects, and $\epsilon_{i s}$ is an error term. In order to control for current behavioral outcomes, we estimated a similar equation:

$$
Y_{i s, t+1}=\alpha+\delta Y_{i s, t}+\beta N C_{i s, t}+\gamma X_{i s, t}+\theta_{s}+\epsilon_{i s}
$$

where $Y_{i s, t+1}$ is the behavioral outcome (e.g., time spent doing homework, disciplinary index, French or math GPA) in the school year $t+1$ and $Y_{i s, t}$ is the behavioral outcome the school year $t$ and $N C_{i s, t}$ is the standardized measure of socio-emotional skills in school year $t$. To test for potential effect of mitigating factors, we ran the same regressions adding age, gender, nationality (french or foreign) and financial aid (yes or no) as dummies. We find that all effects were robust to adding these covariates.

\section{Results}

Reliability of the measures. Assessment of reliability showed that all three measures of socio-emotional skills were similarly reliable, with a small advantage for the teacherreported questionnaire (Table 1). We first calculated the Cronbach's alpha for each measure. For the questionnaires, we computed the inter-item correlation for each socioemotional skill. For the behavioral task, we computed the correlation between each of the three blocks for each variable (number of subtractions attempted and solved, and percentage time spent on solving subtractions versus watching videos). Our results show that the teacher-reported questionnaire had the highest Cronbach alpha (0.93 - 0.94), while the behavioral task had the lowest alpha $(0.44-0.58)$. Values ranging from 0.70 to 0.95 are considered high in the literature (41). Although Cronbach's alpha is widely used in the psychology literature to assess reliability, this measure is sensitive to many factors such as the number of items (42). An alternative and more consistent approach to assess reliability is to assess long-term stability. For a sub-sample of students, we have answers to the questionnaires and behavioral task in both their sixth and seventh grade. We can therefore test the correlation from one year to the next. We expected the longterm stability for the teacher questionnaire to be lowest given that we tested the correlation of answers from two different teachers, whereas the student questionnaire and the task was completed by the same student in both years. Table 1 shows that all methods of measure show similar long term stability (ranging from 0.41 to $0.54, \mathrm{p}=0.01$ ), indicating that these different methods are similarly reliable. These coefficients are similar to the ones found in the literature (43). Although teachers talk amongst themselves and observe the same student in similar situations, it is interesting to note that teachers' answers correlate as much from one year to the next as do the answers of students about themselves. We conclude from this evidence that if anything, the teacher-reported questionnaire is more reliable than the other two methods.

Table 1. Reliability of each method of measure. The table shows the $\alpha$ coefficient corresponding to Cronbach's Alpha for each measure of socio-emotional skill, as well as the number of items includes in the coefficient. The table also shows the partial correlation coefficient from one year to the next for each measure, and the

\begin{tabular}{|c|c|c|c|c|}
\hline & \multicolumn{2}{|c|}{ Cronbach's Alpha } & \multicolumn{2}{|c|}{ Long-term Stability } \\
\hline & $\alpha$ & $\mathrm{N}$ items & Corr & $N$ \\
\hline \multicolumn{5}{|l|}{ Student-reported: } \\
\hline Conscientiousness & 0.70 & 4 & $0.49^{* * *}$ & 1,402 \\
\hline Self-control & 0.82 & 8 & $0.53^{* * *}$ & 1,417 \\
\hline Grit & 0.65 & 8 & $0.48^{* * *}$ & 1,434 \\
\hline \multicolumn{5}{|l|}{ Teacher-reported: } \\
\hline Self-control & 0.94 & 8 & $0.54^{* * *}$ & 906 \\
\hline Grit & 0.93 & 3 & $0.48^{* * *}$ & 905 \\
\hline \multicolumn{5}{|l|}{ Behavioral Task: } \\
\hline Attempted & 0.54 & 3 & $0.49^{* * *}$ & 1,435 \\
\hline Solved & 0.58 & 3 & $0.51^{* * *}$ & 1,435 \\
\hline Time on task & 0.44 & 3 & $0.41^{* * *}$ & 872 \\
\hline
\end{tabular}
sample size for which this correlation was calculated.

Validity of the measures. Contrary to our own expectation and to experts' predictions, our results show that the behavioral task is the least valid method to assess socio-emotional skills in students. We first tested the correlation between each measure and the time spent doing homework. Results in Figure $2 \mathrm{a}$ show that the student questionnaire was most correlated with time spend doing homework $(0.13-0.19, \mathrm{p}=0.01)$ compared to the teacher questionnaire $(0.06-0.08, \mathrm{p}=0.01)$ and the behavioral task $(0.05, \mathrm{p}=0.05)$. However, the $R^{2}$ for these regressions is quite low $\left(R^{2}\right.$ ranging between 0.03 and 0.06). Given that time spent doing homework was a selfreported variable, we can suspect measurement errors due to social desirability bias. Moreover, students prone to social desirability bias may over-declare both time spent on homework and their socio-emotional skills, which may explain the higher correlation between the two. Therefore, we also look at an objective measure of behavior: the discipline index of students, which is based on school administrative records of absenteeism, tardiness, sanctions and disciplinary actions. We find that, as expected, all socio-emotional measures are positively correlated to the disciplinary index, meaning that students who are more conscientious, gritty, or have higher self-control are more disciplined. Results in Figure $2 \mathrm{~b}$ also show that the teacher-reported questionnaire is more strongly correlated with the discipline index $(0.40-0.47, \mathrm{p}=0.01)$ than the student questionnaire $(0.13-0.27, \mathrm{p}=0.01)$ or the behavioral task $(0.15, \mathrm{p}=0.01)$. We perform the same analysis for French and math GPA in panel (c) and (d) and simi- 
larly we find that the teacher questionnaire is most predictive. One possible interpretation for the high correlation between teacher reported questionnaire and observed behavior is that teachers use information on grades, absences, tardiness, sanctions and disciplinary actions when filling the Character Growth Card. Under this interpretation, teachers would not be any better at evaluating socio-emotional skills, they would simply have better access to objective behavioral outcomes. In order to rule out this interpretation, we correlate the teacher-reported questionnaire with behavioral outcomes that the teacher cannot directly observe. Specifically, we check if the teacher-reported questionnaire in a given year correlates with the student's disciplinary index and grades during the following year, controlling for the student's current year outcome. In other words, we test whether each measure of socioemotional skills predicts progress in behavioral outcomes from one year to the next. The theory predicts that students who are more conscientious, gritty, or have more self-control should see higher improvements in their discipline index and GPA than students who are less conscientious, gritty and are more impulsive. We find that, controlling for current current behavioral outcome, the teacher-reported questionnaire consistently predicts behavioral outcomes in the following year (see Figure 3). Once again, teacher-reported questionnaire perform significantly better than student-reported questionnaires or behavioral tasks at predicting future behavior. Importantly, the teacher-reported questionnaire is the only socio-emotional measure that significantly and consistently predicts future academic results, as shown in Figures $3 \mathrm{c}$ and $3 \mathrm{~d}$. We also test whether behavioral measures in grade 6 predict a change in behavior or grades from grade 7 to grade 8 and from grade 8 to grade 9 , and whether behavioral measures in grade 7 predict a change in behavior or grades from grade 8 to grade 9 and find similar results (See Appendix Figures $\mathrm{C} 16$ to $\mathrm{C} 19)$. Taken together, these results show that the teacher-reported questionnaire is a better predictor of future behavioral outcomes that are intimately related to the construct of interest.

Comparing the costs of different methods. For a method of measure to be useful, it must not only be reliable and valid, but it must also be implementable in practice (34). For this reason, we were interested in the relative cost of each method of measure. Our analysis included the cost of hiring research assistants, questionnaire and task support (electronic or paper), data transcription, data cleaning, etc. We estimated the cost of each method to be 44,731 euros for the student questionnaire, 12,907 euros for the teacher questionnaire and 50,191 euros for the behavioral task (see Table 2 for a more detailed breakdown of costs). Although specific costs may vary significantly from one study to the next, a number of factors make behavioral tasks consistently costlier than questionnaires. In addition, one teacher can be surveyed for multiple students, which creates economies of scale. Another way to look at cost is the money spent per student to predict a change of one standard deviation in behavior. Based on their respective predictive power of change in disciplinary index, we find that the teacher questionnaire is only 13 euros per student, while the student questionnaire and the behavioral task are respectively 75 euros and 154 euros per student. Our study suggests that many research teams might be allocating resources to the implementation of behavioral tasks, although cheaper and more accurate methods of measure exist.

Table 2. Breakdown of experimental costs. This table shows the breakdown of costs for each method of measure. Information includes costs pertaining to phoning schools and printing information for consent. Support includes the cost of paper and mailing for teacher questionnaires and digital tablets for student questionnaires and for the behavioral task. The total cost per sd per student is the cost that is needed to observe one standard deviation in the change of behavioral index for one student.

\begin{tabular}{lccc}
\hline \hline & $\begin{array}{c}\text { Student } \\
\text { Questionnaire }\end{array}$ & $\begin{array}{c}\text { Teacher } \\
\text { Questionnaire }\end{array}$ & $\begin{array}{c}\text { Behavioral } \\
\text { Task }\end{array}$ \\
\hline Cost Breakdown: & & & \\
Information & 2,125 & 883 & 2,125 \\
Support & 14,130 & 1,669 & 14,130 \\
Software & 540 & & 6,000 \\
Terrain & 27,936 & & 27,936 \\
Reminder & & 1,746 & \\
Double-entry & & 7,980 & \\
Cleaning & & 630 &
\end{tabular}

\begin{tabular}{lccc} 
Total: & & & \\
Total cost in euros & 44,731 & 12,907 & 50,191 \\
$\begin{array}{l}\text { Per sd per } \\
\text { student in euros }\end{array}$ & 75 & 13 & 154 \\
\hline \hline
\end{tabular}

\section{Discussion}

Validity measures show that the behavioral task systematically under-performed relative to questionnaires to predict outcomes related to socio-emotional skills. In addition, the teacher-reported questionnaire, which was considered the worse method of measurement by experts, showed similar reliability and the highest correlation with behavioral and school outcomes. It is however important to acknowledge limitations coming from our sample. The students who participated in our study are not representative of the entire French population as they attend low income schools. It may be the case that measures from a behavioral task are more reliable and valid for students with affluent backgrounds. It may also be the case that teachers in more affluent schools are less able to assess the socio-emotional skills of their students.

Limits of behavioral tasks. These results contradict experts' predictions and contribute to a growing literature demonstrating the limits of behavioral tasks. For example, a recent study on self-control shows that self-reported measures and inhibition task performance correlate very poorly (44). The authors list three main reasons for the lack of convergence between self-reported measures and behavioral tasks: (1) self-reported questionnaires measure typical performance while tasks measure maximum performance, (2) self-reported measures capture central tendencies of behavior, while behavioral tasks are momentary captures of one time performance, and (3) self-reported questionnaires measure a general cross-domain trait, while a behavioral task focuses on a more narrow manifestation of the trait. A recent 
(a) Homework

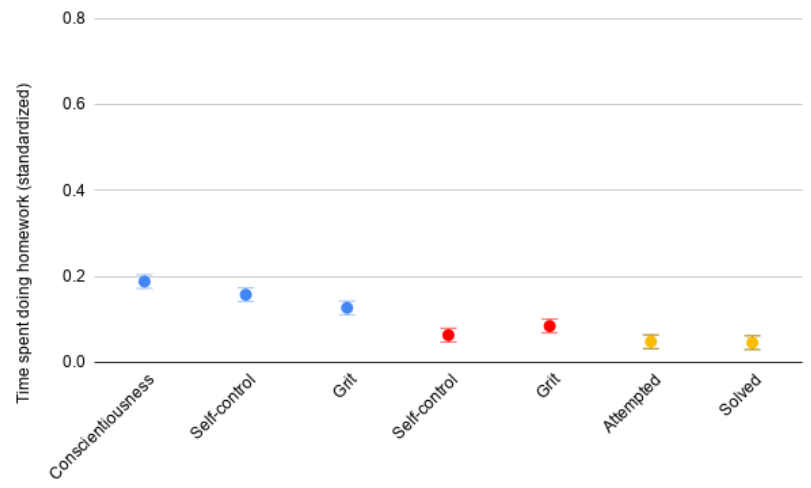

(c) French GPA

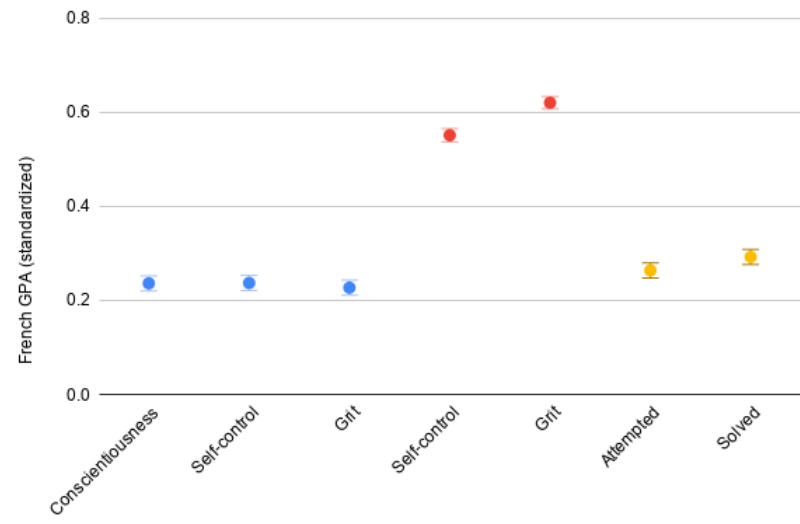

(b) Disciplinary Index

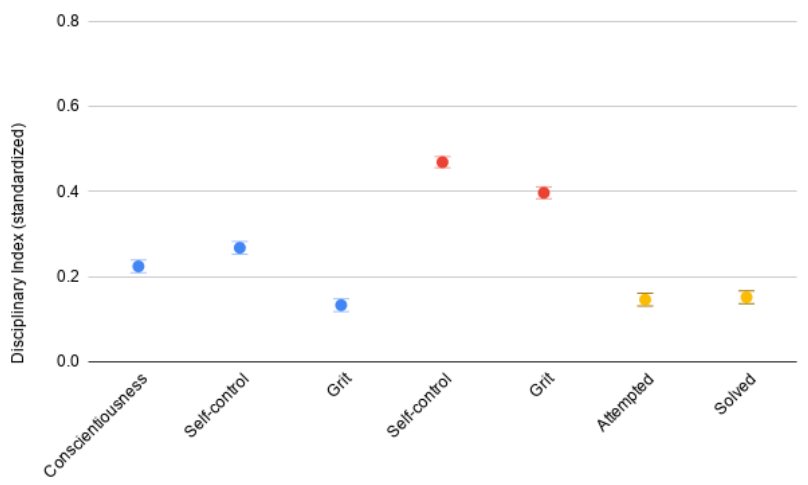

(d) Math GPA

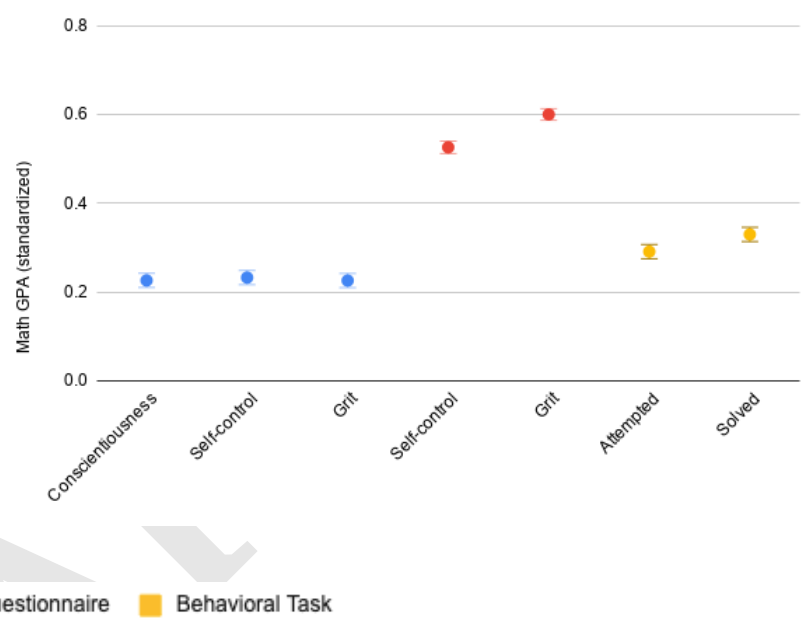

Fig. 2. Standardized correlation coefficients of the ordinary least square regression between socio-emotional skills and students' outcomes $(\mathrm{N}=3,997)$, adjusted for school fixed effects and school year fixed effects (grade 6 and grade 7). Observations with missing outcomes or covariate data were excluded from the sample. The blue points represent the student-reported measures, the red points represent the teacher-reported measures and the yellow points represent the behavioral task measures. The error bars indicate plus or minus one standard deviation. Four outcome measures are presented: time spent doing homework (a), disciplinary index (b), French GPA (c) and Math GPA (d). Time spent doing homework (a) is the standardized student-reported sum of time spent doing homework in the last two days. The regression controls for the day the data was collected. Disciplinary index (b) is the sum of the standardized number of late arrivals, absences, sanctions and disciplinary actions. French GPA (c) is the standardized grade received by the student in French. Math GPA (d) is the standardized grade received by the student in math. The effect is statistically different from 0 for each variable.

study by Enkavi et al. shows that self-regulation measures derived from self-reported questionnaires have higher test-retest reliability than those derived from behavioral tasks (43). A number of studies also show that self-reported measures and behavioral tasks correlate poorly, with self-reported measures correlating better with real-life outcomes $(45,46)$. Finally, behavioral tasks may also suffer from framing effects. For example a study on cooperation shows that performance in a cooperation game is strongly affected by the name given to the game (Community Game, Wall Street Game, Environment Game or simply Game) (47).

Our findings are relevant not only to the study of personality, but also to many other fields measuring individual outcomes. Studies focusing on health outcomes, for instance, have also shown that self-reported measures often predict actual morbidity, mortality or other risk factors better than supposedly more objective measures such as the Global Activity Limitation Index (48-50). Although health institutions have pushed for standardized ways of measuring the health of patients, these might in fact be less accurate than self-reports to predict morbidity and mortality. Including self-reported and third party questionnaires therefore remains valuable, especially in domains where experimental tasks or objective measures may not capture inter-individual differences properly. Studies of happiness and wellness could include third party questionnaires and compare the results with self-reported measures, as behavioral tasks and objective measures are hard to develop in this domain.

Future directions. Does this mean we should stop using behavioral tasks altogether and rely only on self-reported or third-party questionnaires to measure socio-emotional skills? There are no perfect tools of measurement and selecting 
(a) Homework

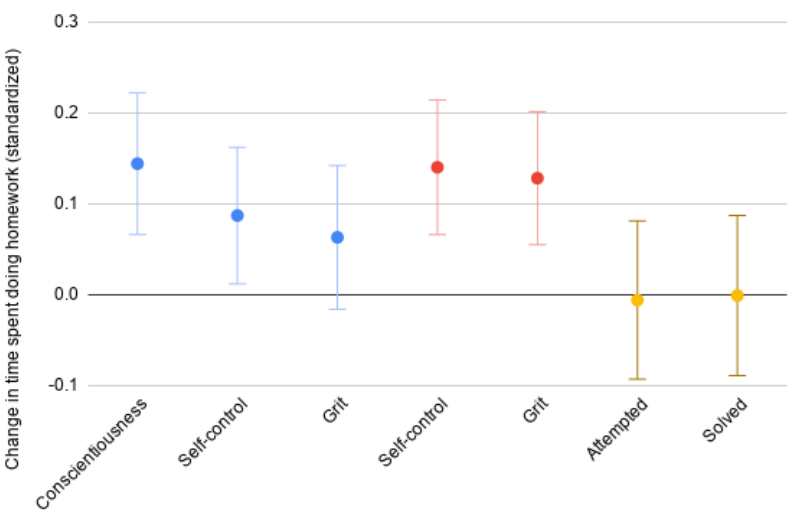

(c) French GPA

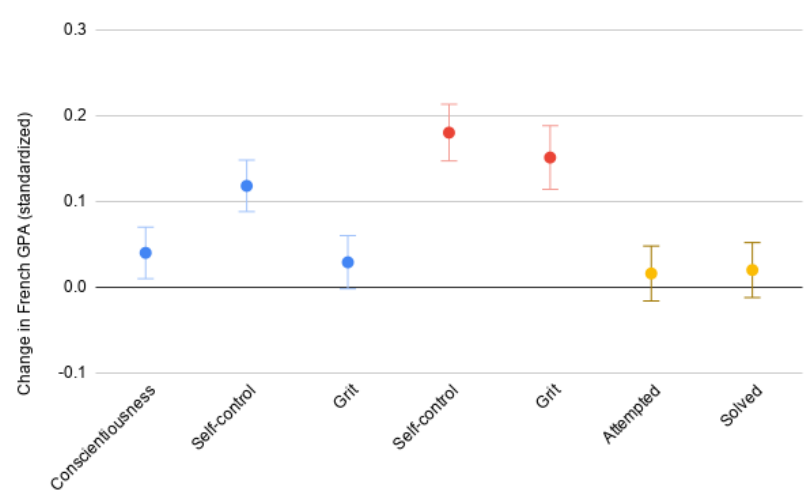

(b) Disciplinary Index

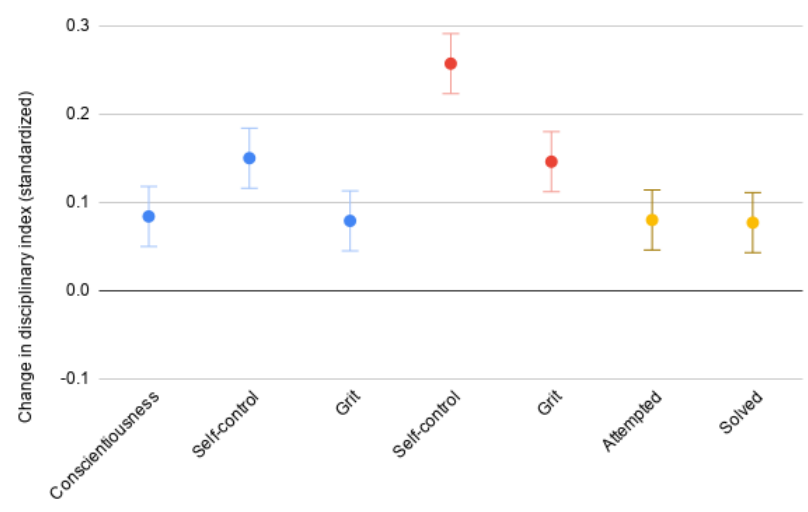

(d) Math GPA

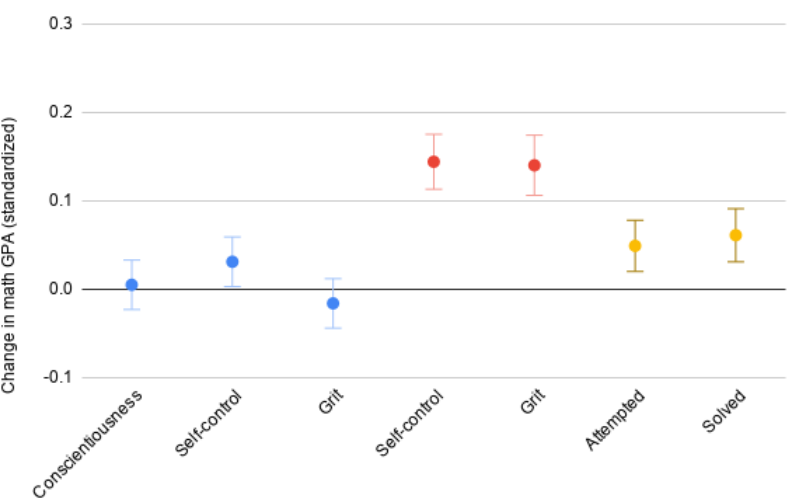

Student Questionnaire

Teacher Questionnaire

Behavioral Task

Fig. 3. Standardized correlation coefficients of the ordinary least square regression between socio-emotional skills and student outcomes, adjusted for school fixed effects and school year fixed effect (grade 6 and grade 7). Observations with missing outcomes or covariate data were excluded from the sample. The blue points represent the student-reported measures, the red points represent the teacherreported measures and the yellow points represent the behavioral task measures. The error bars indicate plus or minus one standard deviation. Four outcome measures are presented: change in time spent doing homework (a), change in disciplinary index (b), change in French GPA (c) and change in math GPA (d). Change in time spent doing homework (a) is the difference between the standardized student-reported sum of time spent doing homework in the last two days in sixth and seventh grade, $\mathrm{N}=191$. The regression controls for the day the data was collected. Change in disciplinary index (b) is the difference between the sum of the standardized number of late arrivals, absences, sanctions and disciplinary actions in sixth and seventh grade, $N=559$. Change in French GPA (c) is the difference between the standardized grade received by the student in French in sixth and seventh grade, $N=491$. Change in math GPA (d) is the difference between the standardized grade received by the student in math in sixth and seventh grade, $\mathrm{N}=527$.

the appropriate one depends on the context of the experiment. For example, in the context of policy evaluation, selfreported questionnaires may not be reliable as the intervention may affect both behavior and the perception of the behavior. For example, a study by Algan, Guyon and Huillery shows that following an intervention to curb school bullying, pupil-reported violence increased but objective and teacherreported violence decreased (51). Based on the self-report only, researchers would have falsely believed that the intervention had a negative impact, when the results are in fact due to a better awareness of bullying among pupils. A teacherreported questionnaire may be a poor predictor of behavior if the teacher has limited contact with the student or has an incentive to bias responses (such as being compensated based on the progression of students). Behavioral tasks can be done repeatedly to obtain a more accurate measure of the average level of the trait being measured, several behavioral tasks can be combined to have a broader understanding of the construct and tasks can be improved to better capture the trait of interest. The most surprising finding of our study was the high validity of the teacher-reported questionnaire, even after controlling for observed behavior. Third-party informants is an interesting yet underused method to study psychological traits. A study by Vazire shows that informants are a cheap way to gather data, that they are often willing to cooperate and provide valid data (52). Yet, one limitation of our study is that attrition is higher for the teacher-reported questionnaire than it is for the student-reported questionnaire, because it is harder to collect data from staff than from the children themselves. New approaches should be developed to ensure 
a high rate of teacher response. Instead of abandoning the use of questionnaires, we should work to improve them, for example by providing a shared reference point, or by ensuring that respondents believe in the confidentiality of their answer, which would minimise the influence of the social desirability bias.

\section{Conclusion}

Psychologists and economists believe that behavioral tasks are the most reliable way to measure socio-emotional skills. Our study allowed to test this intuition by comparing three tools to measure socio-emotional skills: a student-reported questionnaire, a teacher-reported questionnaire and a behavioral task. In addition to comparing the reliability of each tool, access to long term behavioral data allows to compare their construct validity. We found that contrary to experts' predictions, the behavioral task was the least valid tool while the teacher-reported questionnaire was the most valid. Research on socio-emotional skills may suffer from a bias regarding which tools are best to use.

Acknowledgements. C.C. acknowledges funding support from the National Research Agency of France grant ANR-17EURE-0017. Y.A. acknowledges funding support from the European Research Council grant $\mathrm{n}^{\circ} 647870$ (project Sowell). The views expressed in this paper are solely those of the authors and do not necessarily represent those of the funders.

\section{Bibliography}

1. June P Tangney. High Self-Control Predicts Good Adjustment, Less Pathology, Better Grades, and Interpersonal Success. Journal of Personality, 72(2):271-322, 2004.

2. Yuichi Shoda, Walter Mischel, and Philip K Peake. Predicting Adolescent Cognitive and Self-Regulatory Competencies From Preschool Delay of Gratification: Identifying Diagnostic Conditions. Developmental Psychology, 26(6):978-986, 1990.

3. Walter Mischel, Yuichi Shoda, and Philip K Peake. The Nature of Adolescent Competencies Predicted by Preschool Delay of Gratification. Journal of Personality and Social Psychology, 54(4):687-696, 1988.

4. Lauren Eskreis-Winkler, Elizabeth P. Shulman, Scott A. Beal, and Angela L. Duckworth. The grit effect: predicting retention in the military, the workplace, school and marriage. Frontiers in Psychology, 5, 2014. ISSN 1664-1078. doi: 10.3389/fpsyg.2014.00036.

5. Joanne P Rojas and Ellen L Usher. Exploring the Correlations Among Creativity, Grit, and Mathematics Achievement in Socioeconomically Diverse Schools, 2012.

6. Martin R. West, Matthew A. Kraft, Amy S. Finn, Rebecca E. Martin, Angela L. Duckworth, Christopher F. O. Gabrieli, and John D. E. Gabrieli. Promise and Paradox: Measuring Students' Non-Cognitive Skills and the Impact of Schooling. Educational Evaluation and Policy Analysis, 38(1):148-170, 2016. ISSN 0162-3737.

7. Gema Zamarro, Malachi Nichols, Angela L. Duckworth, and Sidney K. D'Mello. Validation of survey effort measures of grit and self-control in a sample of high school students. PLOS ONE, 15(7):e0235396, July 2020. ISSN 1932-6203. doi: 10.1371/journal.pone.0235396.

8. James J Heckman and Yona Rubinstein. The Importance of Noncognitive Skills: Lessons from the GED Testing Program. American Economic Review, 91(2):145-149, May 2001. ISSN 0002-8282. doi: 10.1257/aer.91.2.145.

9. James J. Heckman, Jora Stixrud, and Sergio Urzua. The Effects of Cognitive and Noncognitive Abilities on Labor Market Outcomes and Social Behavior. Journal of Labor Economics, 24(3):411-482, July 2006. ISSN 0734-306X. doi: 10.1086/504455. Publisher: The University of Chicago Press.

10. Lex Borghans, Angela Lee Duckworth, James J. Heckman, and Bas ter Weel. The Economics and Psychology of Personality Traits. Journal of Human Resources, 43(4):9721059, October 2008. ISSN 0022-166X, 1548-8004. doi: 10.3368/jhr.43.4.972. Publisher: University of Wisconsin Press.

11. Giorgio Brunello and Martin Schlotter. Non Cognitive Skills and Personality Traits: Labour Market Relevance and their Development in Education \& Training Systems. IZA Discussion Papers, (5743):47, 2011

12. Christy Lleras. Do skills and behaviors in high school matter? The contribution of noncognitive factors in explaining differences in educational attainment and earnings. Social Science Research, 37(3):888-902, September 2008. ISSN 0049089X. doi: 10.1016/j.ssresearch. 2008.03.004.

13. Robert Agnew, Timothy Brezina, John Paul Wright, and Francis T. Cullen. Strain, personality traits, and delinquency: Extending general strain theory. Criminology, 40(1):43-72, 2002.
14. Brent W. Roberts, Nathan R. Kuncel, Rebecca Shiner, Avshalom Caspi, and Lewis R. Goldberg. The Power of Personality: The Comparative Validity of Personality Traits, Socioeconomic Status, and Cognitive Ability for Predicting Important Life Outcomes. Perspectives on Psychological Science, 2(4):313-345, December 2007. ISSN 1745-6916, 1745-6924. doi: 10.1111/j.1745-6916.2007.00047.x.

15. Mathilde Almlund, Angela Lee Duckworth, James Heckman, and Tim Kautz. Personality Psychology and Economics. IZA Discussion Paper No. 5500, page 255, 2011.

16. Thomas Dohmen, Armin Falk, David Huffman, Uwe Sunde, Jürgen Schupp, and Gert G. Wagner. Individual Risk Attitutes: Measurements, Determinants and Behavior Consequences. Journal of the European Economic Association, 9(3):522-550, June 2011. ISSN 15424766. doi: 10.1111/j.1542-4774.2011.01015.x.

17. Matthias Sutter, Martin G Kocher, Daniela Glätzle-Rützler, and Stefan T Trautmann. Impatience and Uncertainty: Experimental Decisions Predict Adolescents' Field Behavior. American Economic Review, 103(1):510-531, February 2013. ISSN 0002-8282. doi: 10.1257/aer.103.1.510.

18. Marco Castillo, Paul J. Ferraro, Jeffrey L. Jordan, and Ragan Petrie. The today and tomorrow of kids: Time preferences and educational outcomes of children. Journal of Public Economics, 95(11):1377-1385, December 2011. ISSN 0047-2727. doi: 10.1016/j.jpubeco. 2011.07.009.

19. Bart H. H. Golsteyn, Hans Grönqvist, and Lena Lindahl. Adolescent Time Preferences Predict Lifetime Outcomes. The Economic Journal, 124(580): F739-F761, 2014. ISSN 1468-0297. doi: 10.1111/ecoj.12095. _eprint: https://onlinelibrary.wiley.com/doi/pdf/10.1111/ecoj.12095.

20. T. E. Moffitt, L. Arseneault, D. Belsky, N. Dickson, R. J. Hancox, H. Harrington, R. Houts, R. Poulton, B. W. Roberts, S. Ross, M. R. Sears, W. M. Thomson, and A. Caspi. A gradient of childhood self-control predicts health, wealth, and public safety. Proceedings of the National Academy of Sciences, 108(7):2693-2698, February 2011. ISSN 0027-8424, 1091-6490. doi: 10.1073/pnas.1010076108.

21. Yann Algan, Élise Huillery, and Corinne Prost. Confiance, coopération et autonomie : pour une école du xxie siècle. Notes du conseil d'analyse économique, 48(3):1, 2018. ISSN 2273-8525, 2270-2385. doi: 10.3917/ncae.048.0001.

22. Sule Alan, Teodora Boneva, and Seda Ertac. Randomized Educational Intervention on Grit. page 66, 2017.

23. Tim Kautz, James J. Heckman, Ron Diris, and L Borghans. Fostering and measuring skills: Improving cognitive and non-cognitive skills to promote lifetime success. National Bureau of Economic Research., No. w20749, 2014.

24. David S. Yeager, Paul Hanselman, Gregory M. Walton, Jared S. Murray, Robert Crosnoe, Chandra Muller, Elizabeth Tipton, Barbara Schneider, Chris S. Hulleman, Cintia P. Hinojosa, David Paunesku, Carissa Romero, Kate Flint, Alice Roberts, Jill Trott, Ronaldo lachan, Jenny Buontempo, Sophia Man Yang, Carlos M. Carvalho, P. Richard Hahn, Maithreyi Gopalan, Pratik Mhatre, Ronald Ferguson, Angela L. Duckworth, and Carol S. Dweck. A national experiment reveals where a growth mindset improves achievement. Nature, 573(7774):364-369, September 2019. ISSN 0028-0836, 1476-4687. doi: 10.1038/s41586-019-1466-y.

25. Élise Huillery, Adrien Bouguen, Axelle Charpentier, Yann Algan, and Coralie Chevallier. The Impact of a Large-Scale Mindset Intervention on School Outcomes: Experimental Evidence from France. Mimeo, 2020

26. Milos Kankaras and Javier Suarez-Alvarez. Assessment framework of the OECD Study on Social and Emotional Skills. OECD Education Working Papers 207, October 2019. Series: OECD Education Working Papers Volume: 207.

27. Eric Loken and Andrew Gelman. Measurement error and the replication crisis. Science, 355(6325):584-585, February 2017. ISSN 0036-8075, 1095-9203. doi: 10.1126/science. aal3618.

28. Yuanyuan Chen, Shuaizhang Feng, James J. Heckman, and Tim Kautz. Sensitivity of selfreported noncognitive skills to survey administration conditions. Proceedings of the National Academy of Sciences, 117(2):931-935, January 2020. ISSN 0027-8424, 1091-6490. doi: 10.1073/pnas.1910731117.

29. Rachid Laajaj, Karen Macours, Daniel Alejandro Pinzon Hernandez, Omar Arias, Samuel D. Gosling, Jeff Potter, Marta Rubio-Codina, and Renos Vakis. Challenges to capture the big five personality traits in non-WEIRD populations. Science Advances, 5(7):eaaw5226, July 2019. ISSN 2375-2548. doi: 10.1126/sciadv.aaw5226.

30. Rachid Laajaj and Karen Macours. Measuring Skills in Developing Countries. Journal of Human Resources, pages 1018-9805R1, October 2019. ISSN 0022-166X, 1548-8004. doi: 10.3368/jhr.56.4.1018-9805R1. Publisher: University of Wisconsin Press.

31. Junhua Dang, Kevin M. King, and Michael Inzlicht. Why Are Self-Report and Behavioral Measures Weakly Correlated? Trends in Cognitive Sciences, page S1364661320300255, February 2020. ISSN 13646613. doi: 10.1016/j.tics.2020.01.007.

32. Stefano Palminteri and Coralie Chevallier. Can We Infer Inter-Individual Differences in RiskTaking From Behavioral Tasks? Frontiers in Psychology, 9:2307, November 2018. ISSN 1664-1078. doi: 10.3389/fpsyg.2018.02307.

33. Angela L. Duckworth and David Scott Yeager. Measurement Matters: Assessing Personal Qualities Other Than Cognitive Ability for Educational Purposes. Educational Researcher, 44(4):237-251, May 2015. ISSN 0013-189X, 1935-102X. doi: 10.3102/0013189X15584327.

34. James Heckman, Tomáš Jagelka, and Timothy Kautz. Some Contributions of Economics to the Study of Personality. IZA Discussion Paper No. 12753, page 79, November 2019. doi: $10.3386 / \mathrm{w} 26459$

35. Olivier P John and Sanjay Srivastava. John, O. P., \& Srivastava, S. (1999). The Big Five trait taxonomy: History, measurement, and theoretical perspectives. Handbook of personality: Theory and research, 2:102-138, 1999.

36. Angela Lee Duckworth and Patrick D. Quinn. Development and Validation of the Short Grit Scale (Grit-S). Journal of Personality Assessment, 91(2):166-174, February 2009. ISSN 0022-3891, 1532-7752 doi: 10.1080/00223890802634290.

37. Eli Tsukayama, Angela Lee Duckworth, and Betty Kim. Domain-specific impulsivity in school-age children. Developmental Science, 16(6):879-893, May 2013. ISSN 1363755X. doi: $10.1111 /$ desc. 12067

38. Daeun Park, Eli Tsukayama, Geoffrey P. Goodwin, Sarah Patrick, and Angela L. Duckworth. 
A tripartite taxonomy of character: Evidence for intrapersonal, interpersonal, and intellectual competencies in children. Contemporary Educational Psychology, 48:16-27, January 2017. ISSN 0361476X. doi: 10.1016/j.cedpsych.2016.08.001.

39. Brian M. Galla, Benjamin D. Plummer, Rachel E. White, David Meketon, Sidney K. D’Mello, and Angela L. Duckworth. The Academic Diligence Task (ADT): assessing individual differences in effort on tedious but important schoolwork. Contemporary Educational Psychology, 39(4):314-325, October 2014. ISSN 0361476X. doi: 10.1016/j.cedpsych.2014.08.001.

40. Stefano DellaVigna, Devin Pope, and Eva Vivalt. Predict science to improve science. Science, 366(6464):428-429, October 2019. ISSN 0036-8075, 1095-9203. doi: 10.1126/ science.aaz1704.

41. Lf J Cronbach. Coefficient alpha and the internal structure of tests. Psychometrika, 16(3) 297-334, 1951

42. Robert R. McCrae, John E. Kurtz, Shinji Yamagata, and Antonio Terracciano. Internal Consistency, Retest Reliability, and Their Implications for Personality Scale Validity. Personality and Social Psychology Review, 15(1):28-50, February 2011. ISSN 1088-8683, 1532-7957. doi: $10.1177 / 1088868310366253$

43. A. Zeynep Enkavi, lan W. Eisenberg, Patrick G. Bissett, Gina L. Mazza, David P. MacKinnon, Lisa A. Marsch, and Russell A. Poldrack. Large-scale analysis of test-retest reliabilities of self-regulation measures. Proceedings of the National Academy of Sciences, 116(12): 5472-5477, March 2019. ISSN 0027-8424, 1091-6490. doi: 10.1073/pnas.1818430116.

44. Lasse Wennerhold and Malte Friese. Why Self-Report Measures of Self-Control and Inhibition Tasks Do Not Substantially Correlate. Collabra: Psychology, 6(1):9, January 2020. ISSN 2474-7394. doi: 10.1525/collabra.276.

45. Kasey G. Creswell, Aidan G. C. Wright, Janine D. Flory, Carillon J. Skrzynski, and Stephen B. Manuck. Multidimensional assessment of impulsivity-related measures in relation to externalizing behaviors. Psychological Medicine, 49(10):1678-1690, July 2019 ISSN 0033-2917, 1469-8978. doi: 10.1017/S0033291718002295.

46. Renato Frey, Andreas Pedroni, Rui Mata, Jörg Rieskamp, and Ralph Hertwig. Risk preference shares the psychometric structure of major psychological traits. Science Advances, 3 (10):e1701381, October 2017. ISSN 2375-2548. doi: 10.1126/sciadv.1701381.

47. Elizabeth Bernold, Elisabeth Gsottbauer, Kurt A. Ackermann, and Ryan O. Murphy. Socia Framing and Cooperation: The Roles and Interaction of Preferences and Beliefs. SSRN Electronic Journal, 2015. ISSN 1556-5068. doi: 10.2139/ssrn.2557927.

48. Lisa M. Christian, Jay lams, Kyle Porter, and Binnaz Leblebicioglu. Self-Rated Health among Pregnant Women: Associations with Objective Health Indicators, Psychological Functioning, and Serum Inflammatory Markers. Annals of Behavioral Medicine, 46(3):295309, December 2013. ISSN 0883-6612, 1532-4796. doi: 10.1007/s12160-013-9521-7.

49. Karen B. DeSalvo, Nicole Bloser, Kristi Reynolds, Jiang He, and Paul Muntner. Mortality prediction with a single general self-rated health question: A meta-analysis. Journal of General Internal Medicine, 21(3):267-275, March 2006. ISSN 0884-8734, 1525-1497. doi: 0.1111/j.1525-1497.2005.00291.x.

50. Julio Cabrero-García and Rocío Juliá-Sanchis. The Global Activity Limitation Index mainly measured functional disability, whereas self-rated health measured physical morbidity. Journal of Clinical Epidemiology, 67(4):468-476, April 2014. ISSN 08954356. doi: 10.1016/j.jclinepi.2013.10.005.

51. Yann Algan, Nina Guyon, and Elise Huillery. Comment lutter contre la violence et le harcèlement à l'école et au collège ?: Effets du dispositif de médiation sociale France Médiation et d'un dispositif de prise de conscience du niveau de violence. Technical Report info:hdl:2441/1qg9pik67s9r8a23gq9bparglm, Sciences Po, April 2015. Publication Title: Sciences Po publications.

52. Simine Vazire. Informant reports: A cheap, fast, and easy method for personality assessment. Journal of Research in Personality, 40(5):472-481, October 2006. ISSN 00926566. doi: 10.1016/j.jrp.2005.03.003. 